\title{
Cerebral Hemodynamics in Premature Infants
}

\author{
Christopher J. Rhee, Danielle R. Rios, Jeffrey R. Kaiser*, and Ken Brady ${ }^{\dagger}$ \\ Section of Neonatology, Department of Pediatrics, Texas Children's Hospital, Baylor College of Medicine, Houston, TX, United States \\ Departments of Pediatrics, Obstetrics and Gynecology*, Hershey Medical Center, Penn State College of Medicine, Milton S, Hershey, PA, \\ United States \\ Section of Neonatology, Departments of Pediatrics, Critical Care Medicine and Anesthesiology ${ }^{\dagger}$, Texas Children's Hospital, Baylor College \\ of Medicine, Houston, TX, United States
}

\section{ABSTRACT}

Extremely low birth weight infants remain at increased risk of intraventricular hemorrhage from the fragile vascular bed of the germinal matrix; the roles of hypotension (ischemia) and reperfusion (hyperemia) in the development of intraventricular hemorrhage are still debated. Cerebrovascular pressure autoregulation protects the brain by maintaining constant cerebral blood flow despite changes in blood pressure. The ontogeny of cerebrovascular pressure autoregulation has not been well established and uncertainty remains about the optimal arterial blood pressure required to support brain perfusion. Another important aspect of premature cerebral hemodynamics is the critical closing pressure--the arterial blood pressure at which cerebral blood flow ceases. Interestingly, in premature infants, the critical closing pressure approximates the mean arterial blood pressure. Often in this unique population, cerebral blood flow occurs only during systole when the diastolic arterial blood pressure is equal to the critical closing pressure. Moreover, the diastolic closing margin, a metric of cerebral perfusion that normalizes diastolic arterial blood pressure to the critical closing pressure, may be a better measure than arterial blood pressure for defining cerebral perfusion in premature infants. Elevated diastolic closing margin has been associated with intraventricular hemorrhage. This review summarizes the current state of understanding of cerebral hemodynamics in premature infants.

Key Words: Premature, Intraventricular hemorrhage, Cerebral autoregulation, Critical closing pressure, Diastolic closing margin

\section{INTRODUCTION}

Extremely low birth weight (ELBW, birth weight $\leq 1,000 \mathrm{~g}$ ) infants are at high risk for developing brain injury early in life. Intraventricular hemorrhage (IVH) is the most common form of brain injury, and its incidence is inversely proportional to gestational age (GA) and birth weight (BW). IVH is associated with long-term neurodevelopmental delay, poor cognitive performance, visual and hearing impairment, epilepsy and cerebral palsy ${ }^{11}$. Despite impro-
Received: 16 December 2017

Revised: 21 January 2018

Accepted: 24 January 2018

Correspondence to: Christopher J.

Rhee

Department of Pediatrics, Texas

Children's Hospital, 6621 Fannin

Street 6-104, Houston, TX 77030,

United States

Tel: +1-832-826-1380

Fax: +1-832-825-2799

E-mail: cjrhee@texaschildrens.org

Copyright(c)

By Korean Society of Neonatology.

All right reserved.

This is an Open-Access article distributed under the terms of the Creative Commons Attribution Non-Commercial License (http://creativecommons.org/licenses/ by-nc/4.0), which permits unrestricted non-commercial use, distribution, and reproduction in any medium, provided the original work is properly cited. 
vements in overall ELBW infant survival, they remain at high risk for poor neurodevelopmental outcomes.

The thin-walled, immature vessels of the germinal matrix contribute to the increased risk for IVH in ELBW infants ${ }^{2,3)}$. In addition, hypotension (ischemia) followed by reperfusion (hyperemia) have been implicated in the pathogenesis of IVH in human premature infants ${ }^{4-7)}$ an in experimental animal models ${ }^{8,9)}$. A delicate balance is required to maintain adequate cerebral perfusion while avoiding ischemia or hyperemia, both of which may result in brain injury.

Arterial blood pressure (ABP) is the most frequently monitored parameter for assessment of hemodynamics in ELBW infants however, there is little-to-no correlation between systemic blood flow and $\mathrm{ABP}$, as shock occurs even with normal $\mathrm{ABP}^{10,11)}$. The goal of $\mathrm{ABP}$ management in premature infants is to maintain adequate perfusion to the brain and other vital organs. Despite this objective, neonatologists have been unable to determine evidencebased $\mathrm{ABP}$ values or thresholds to define hypotension, the most appropriate treatments and whether treatment is even required for some infants. This highlights the importance of defining optimal ABP management that is supportive of cerebral and other $\operatorname{organ}_{\text {perfusion }}{ }^{12,13)}$.

In order to define optimal brain perfusion, several key aspects of cerebral hemodynamics must be included to understand this complex physiology: cerebrovascular pressure autoregulation, critical closing pressure ( $\mathrm{CrCP}$ ) and the diastolic closing margin (DCM). Cerebrovascular pressure autoregulation protects the brain by maintaining constant cerebral blood flow (CBF) across a wide range of ABPs and has been shown to be impaired in sick premature infants ${ }^{14)}$. Determining the effective cerebral perfusion pressure requires knowledge of the $\mathrm{CrCP}$, the $\mathrm{ABP}$ at which the $\mathrm{CBF}$ ceases. When diastolic $\mathrm{ABP}$ is equal to the $\mathrm{CrCP}, \mathrm{CBF}$ occurs only during systole. Therefore, a metric is needed that accounts for CrCP and the observations of passive or absent CBF during diastole. The DCM, diastolic $\mathrm{ABP}$ minus $\mathrm{CrCP}$, provides a metric of effective cerebral perfusion pressure, and when elevated, has been associated with IVH in premature infants ${ }^{15)}$.

This review summarizes the current state of understanding of cerebral hemodynamics in premature infants.

\section{CEREBROVASCULAR PRESSURE AUTOREGULATION}

Mammalian cerebral vasculature muscularity develops at approximately 0.65 gestation (at approximately 26 weeks' gestation in humans ${ }^{16,17)}$. Cerebrovascular pressure autoregulation protects the brain during transient fluctuations in ABP from diminished or excessive $\mathrm{CBF}$ over a wide range of ABPs. An autoregulatory plateau exists whereby $\mathrm{CBF}$ is held constant across changing $\mathrm{ABP}$ (Figure 1). In addition, both an upper and a lower limit exist on the autoregulation curve. Above the upper limit, if the ABP increases, the $\mathrm{CBF}$ increases and below the lower limit, if the $\mathrm{ABP}$ decreases, the CBF decreases.

Importantly, autoregulation is mediated by vascular reactivity, which is defined as low-frequency $(0-0.04 \mathrm{~Hz})$ diameter changes in resistance vessels in response to changes in $\mathrm{ABP}^{18)}$. Premature infants maintain adequate cerebral perfusion across a wide $\mathrm{ABP}$ range from approximately 24 to $39 \mathrm{~mm} \mathrm{Hg}$, and evidence exists that many premature infants have periods of intact autoregulation ${ }^{19-22)}$. At ABPs below and above the autoregulatory plateau, CBF becomes pressure passive. However, cerebral autoregulation is likely increasingly impaired with decreasing GA and BW, and infants with impaired autoregulation more commonly develop $\mathrm{IVH}^{20,23,24)}$. In addition, cerebral autoregulation in premature infants is influenced by hypercapnia, surfactant administration and other neonatal intensive care procedures ${ }^{19,25-27)}$. Finally, impaired autore-

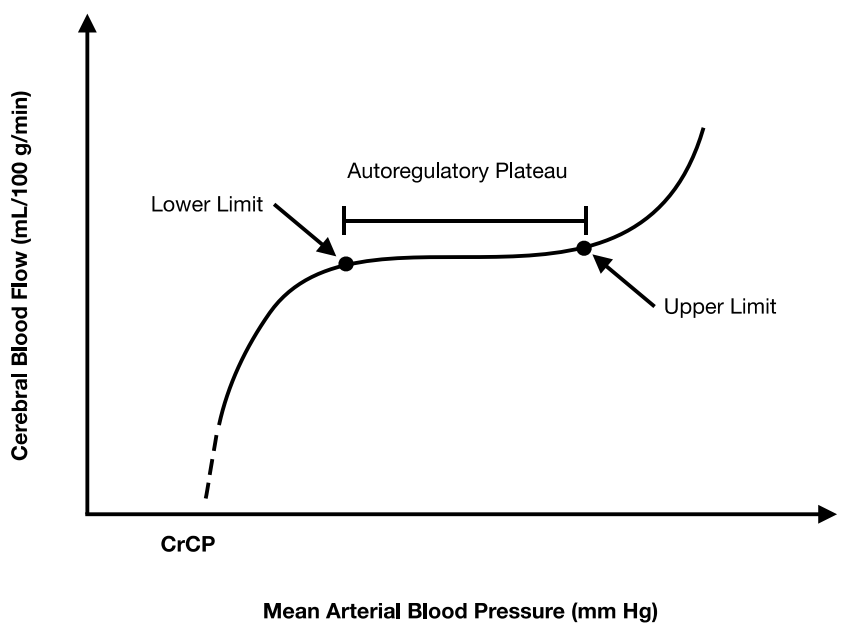

Figure 1. Autoregulation curve. Autoregulatory plateau is shown as the flat part of the curve where cerebral blood flow is constant across varying blood pressure. The upper and lower limit of autoregulation are depicted, above and below which the brain is more susceptible to injury. The critical closing pressure ( $\mathrm{CrCP})$ is the arterial blood pressure at which the cerebral blood flow is zero. 
gulation was associated with increased mortality in this at-risk population $^{28,29)}$.

While the capacity for intact autoregulation has been demonstrated in premature infants using both transcranial Doppler ultrasound and near-infrared spectroscopy techniques, there is limited information about its ontogeny ${ }^{21)}$. In a re-analysis of previously published data, regulation of CBF velocity (CBFV) was examined in 179 premature infants with GA from 23-33 weeks' gestation comparing systolic, diastolic and mean CBFV patterns separately ${ }^{30)}$. Vascular resistance changes mediating autoregulation were effective at regulating systolic $\mathrm{CBFV}$ while diastolic $\mathrm{CBFV}$ was both low and passive to ABP changes. In addition, there was an association between increasing GA and intact cerebral autoregulation during systole.

The results of this study imply three practicalities related to premature cerebrovascular pressure autoregulation: 1) When Doppler ultrasound is used to study autoregulation in premature infants, those $<26$ weeks are likely to demonstrate pressurepassivity regardless of care strategy. Therefore, autoregulation monitoring with Doppler is not likely to elucidate optimal care strategies for most ELBW infants. 2) If Doppler is used to study autoregulation in premature infants, evaluation of the systolic phase of the cardiac cycle is more likely to demarcate optimal care strategies than evaluation of mean values across the cardiac cycle. Premature infants demonstrate an ability to autoregulate the surge of CBFV during systole before any apparent autoregulation of diastolic CBFV. 3) ABP is a poor surrogate of cerebral perfusion pressure in premature infants.

\section{CRITICAL CLOSING PRESSURE}

$\mathrm{CrCP}$ is the $\mathrm{ABP}$ where $\mathrm{CBF}$ ceases due to vascular collapse, and it is posited to be the sum of vascular wall tension and intracranial pressure $^{31)}$. In concept, $\mathrm{CrCP}$ is a factor for the normalization of ABP to an "effective cerebral perfusion pressure" or "closing margin," whereby "effective cerebral perfusion pressure" is equal to $\mathrm{ABP}$ minus $\mathrm{CrCP}^{32,33)}$. CrCP in infants ranges from $24-33 \mathrm{~mm} \mathrm{Hg}$, similar to reported $\mathrm{CrCP}$ values in mature subjects ${ }^{34,35)}$. Low ABP in ELBW infants results in a strikingly low effective cerebral perfusion pressure. Small variances of $\mathrm{CrCP}$ and $\mathrm{ABP}$, therefore, may result in more dramatic changes in the premature infant's effective cerebral perfusion pressure. This important factor confounds the clinical usefulness of ABP alone as a marker of adequate cerebral perfusion. Moreover, when compared to term infants and adults, the closing margin has greater relevance accounting for the low $\mathrm{ABP}$ of premature infants (Figure 2).

$\mathrm{CrCP}$ has been calculated using two methods. The first method used a model of linear regression plotting multiple measures of mean $\mathrm{CBFV}$ and mean $\mathrm{ABP}$. The $\mathrm{CrCP}$ was then determined as the mean ABP where the linear regression line crossed the $\mathrm{x}$-axis ${ }^{35)}$. More recently, a new method to calculate CrCP using ABP and CBFV tracings was proposed ${ }^{33)}$. In this method, CBFV is described by alternating flow velocity at the frequency of the cardiac cycle, and $\mathrm{CrCP}$ is derived from an equation of impedance to flow velocity.

In premature infants, CrCP increased significantly from 23-31 weeks' gestation at a rate of $1.4 \mathrm{~mm} \mathrm{Hg}$ per week of gestation ${ }^{36)}$. An individual infant's ability to tolerate low ABP without global cerebral infarct or hemorrhage may be related to the low $\mathrm{CrCP}$ observed in this population. While there may be limitations to measuring $\mathrm{CrCP}$, it will likely have relevance to identifying those premature infants most at risk for brain injury.

\section{DIASTOLIC CLOSING MARGIN}

The "effective cerebral perfusion" or "closing margin" can be determined for any phase of the cardiac cycle by subtracting the

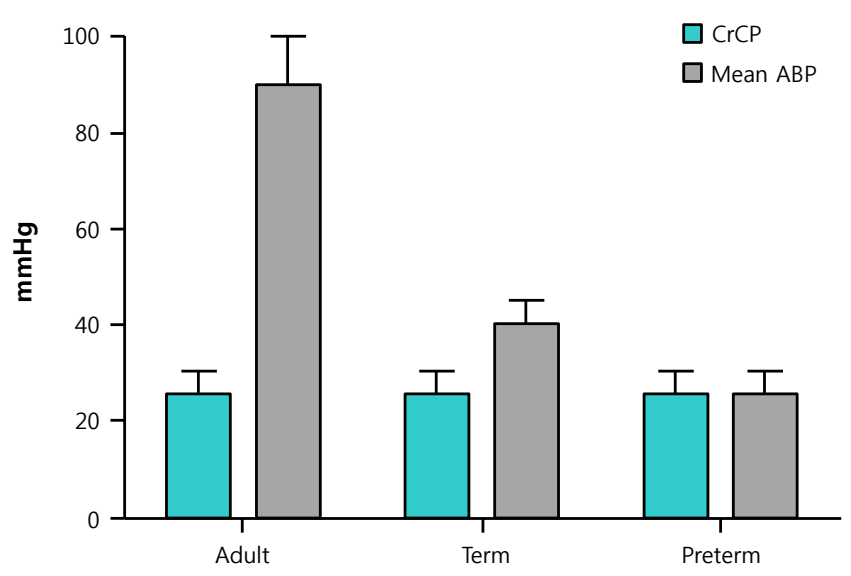

Figure 2. Comparison of $\mathrm{CrCP}$ and mean $\mathrm{ABP}$ in adults, term and preterm infants. $\mathrm{CrCP}$ is near mean $\mathrm{ABP}$ in preterm infants demonstrating a low "effective cerebral perfusion pressure" relative to the range of $\mathrm{CrCP}$. The effective cerebral perfusion pressure is defined as $\mathrm{ABP}$ minus $\mathrm{CrCP}$. This may be the reason premature infants tolerate low $\mathrm{ABP}$ without compromised $\mathrm{CBF}$. Abbreviations: $\mathrm{CrCP}$, critical closing pressure; $\mathrm{ABP}$, arterial blood pressure; $\mathrm{CBF}$, cerebral blood flow. 


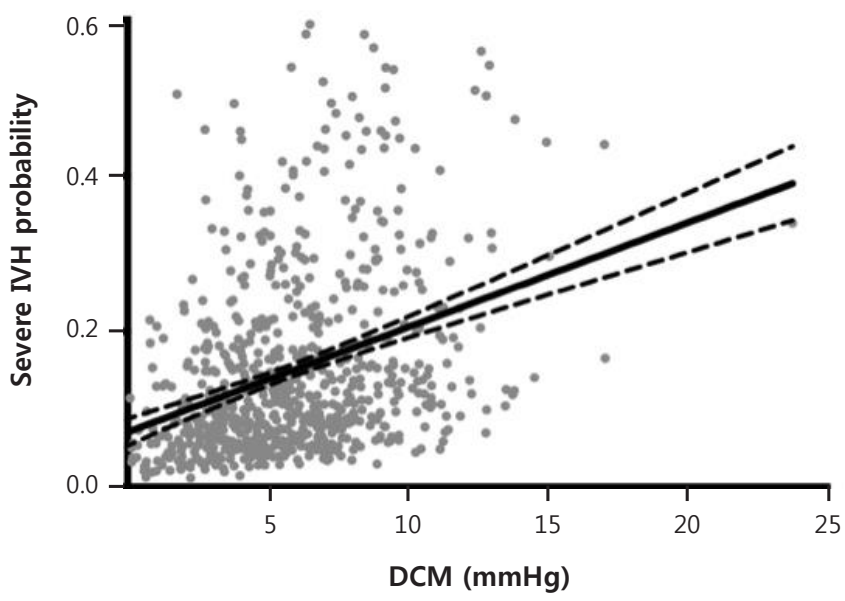

Figure 3. DCM is associated with severe IVH $(P<0.0001)$. For an increase in DCM by $1 \mathrm{mmHg}$, the risk for severe IVH increases by $15 \%$. Abbreviations: DCM, diastolic closing margin; IVH, intraventricular hemorrhage.

CrCP from systolic, mean or diastolic ABP. In premature infants, $\mathrm{CBF}$ is often passive to $\mathrm{ABP}$ or absent during diastole, and this unique physiology has only been described in the presence of severe neuropathology in mature subjects ${ }^{37)}$. The DCM, diastolic ABP minus $\mathrm{CrCP}$, provides a metric of "effective cerebral perfusion" that can be related to premature brain injury.

In premature infants, increased DCM was associated with developing severe IVH (Grade 3-4) $(P<0.0001 \text {, Figure } 3)^{15)}$. Interestingly, when comparing infants with severe IVH to those with nonsevere IVH, both mean CBFV and mean ABP were not different; the DCM, however, was statistically higher in those infants with severe IVH $(P=0.0063)$. This result may be evidence for a reperfusion injury associated with the pathogenesis of IVH. By simply having a 1-mm Hg increase in DCM, there was a 15\% increased odds of developing severe IVH. Further, a 5-mm Hg increase in DCM was associated with an $89 \%$ increased odds of developing severe IVH. Thus, DCM may be a better measure than ABP for defining premature infant cerebral perfusion.

Further studies are needed to corroborate our findings that elevated DCM can be predictive of developing severe IVH in atrisk premature infants. More comprehensive physiologic monitoring data is necessary and may include targeted neonatal echocardiography, near-infrared spectroscopy, transcranial Doppler ultrasound and amplitude-integrated electroencephalography.

\section{SUMMARY}

Premature infants remain at high-risk for the development of IVH early in life. This unique population has low and almost always pressure-passive diastolic CBF. By contrast, the regulation of systolic CBFV by pressure autoregulation develops between 23 and 33 weeks' gestation. Another important related aspect of cerebral hemodynamics is the CrCP. CrCP can serve as a zeropoint reference for determining cerebral perfusion pressure, and it increases gradually with advancing gestational age making it a very useful metric in understanding cerebral perfusion in premature infants. The low $\mathrm{CrCP}$ observed in very premature infants may explain their ability to tolerate low ABP without global cerebral infarct or hemorrhage. By using the CrCP to normalize diastolic $\mathrm{ABP}$ to an "effective cerebral perfusion pressure," DCM was shown when elevated to be strongly associated with severe IVH when $\mathrm{ABP}$ alone was not predictive of neurologic injury. Measurement of $\mathrm{CrCP}$ and DCM may be more useful than $\mathrm{ABP}$ to define individualized hemodynamic management and mitigate the risk for brain injury in this vulnerable population.

\section{CONFLICTS OF INTEREST AND SOURCE OF FUNDING}

The authors declare no conflict of interest. Christopher Rhee is supported by the NIH NINDS (1K23NS091382-01A1) and the NIH Loan Repayment Program (K23NS091382). He was also previously supported by the Chao Physician Scientist Award (Baylor College of Medicine). Danielle Rios is supported by the NIH NHLBI (1K23HL130522-01) and the NIH Loan Repayment Program (K23HLI120522). The authors declare no other financial support.

\section{REFERENCES}

1) Hack M. Young adult outcomes of very-low-birth-weight children. Semin Fetal Neonatal Med 2006;11:127-37.

2) Volpe JJ. Intraventricular hemorrhage in the premature infant-current concepts. Part I. Ann Neurol 1989;25:3-11.

3) Volpe JJ. Intraventricular hemorrhage in the premature infant-current concepts. Part II. Ann Neurol 1989;25:109-16.

4) Osborn DA, Evans N, Kluckow M. Clinical detection of low upper body blood flow in very premature infants using blood pressure, capillary refill time, and central-peripheral tempera- 
ture difference. Arch Dis Child Fetal Neonatal Ed 2004;89: F16873.

5) Watkins AM, West CR, Cooke RW. Blood pressure and cerebral haemorrhage and ischaemia in very low birthweight infants. Early Hum Dev 1989;19:103-10.

6) Kluckow M, Evans N. Superior vena cava flow in newborn infants: a novel marker of systemic blood flow. Arch Dis Child Fetal Neonatal Ed 2000;82:F182-7.

7) Kluckow M, Evans N. Low systemic blood flow in the preterm infant. Semin Neonatol 2001;6:75-84.

8) Ment LR, Stewart WB, Duncan CC, Pitt BR, Rescigno A, Cole J. Beagle puppy model of perinatal cerebral infarction. J Neurosurg 1985;63:441-7.

9) Ment LR, Stewart WB, Duncan CC, Pitt BR. Beagle puppy model of perinatal cerebral insults. J Neurosurg 1986;65:847-50.

10) Soleymani S, Borzage M, Noori S, Seri I. Neonatal hemodynamics: monitoring, data acquisition and analysis. Expert Rev Med Devices 2012;9:501-11.

11) Osborn DA, Evans N, Kluckow M. Clinical detection of low upper body blood flow in very premature infants using blood pressure, capillary refill time, and central-peripheral temperature difference. Arch Dis Child Fetal Neonatal Ed 2004;89: F168-F73.

12) Laughon M, Bose C, Allred E, O'Shea TM, Marter LJV, Bednarek F, et al. Factors associated with treatment for hypotension in extremely low gestational age newborns during the first postnatal week. Pediatrics 2007;119:273-80.

13) Al-Aweel I, Pursley D, Rubin L, Sharh B, Weisberger S, Richardson $\mathrm{D}$. Variations in prevalence of hypotension, hypertension, and vasopressor use in NICUs. J Perinatol 2001;21:272-8.

14) Lou H, Skov H, Pedersen H. Low cerebral blood flow: a risk factor in the neonate. J Pediatr 1979;95:606-9.

15) Rhee CJ, Kaiser JR, Rios DR, Kibler KK, Easley RB, Andropoulos $\mathrm{DB}$, et al. Elevated diastolic closing margin is associated with intraventricular hemorrhage in premature infants. J Pediatr 2016;174:52-6.

16) Szymonowicz W, Walker A, Yu V, Stewart M, Cannata J, Cussen L. Regional cerebral blood flow after hemorrhagic hypotension in the preterm, near-term, and newborn lamb. Pediatr Res 1990; 28:361-6.

17) Helou S, Koehler RC, Gleason CA, Jones MD, Jr., Traystman RJ. Cerebrovascular autoregulation during fetal development in sheep. Am J Physiol 1994;266:H1069-74.

18) Lee JK, Kibler KK, Benni PB, Easley RB, Czosnyka M, Smielewski $\mathrm{P}$, et al. Cerebrovascular reactivity measured by near-infrared spectroscopy. Stroke 2009;40:1820-6.

19) Kaiser JR, Gauss CH, Williams DK. Surfactant administration acutely affects cerebral and systemic hemodynamics and gas exchange in very-low-birth-weight infants. J Pediatr 2004;
144:809-14.

20) Tsuji M, Saul JP, du Plessis A, Eichenwald E, Sobh J, Crocker R, et al. Cerebral intravascular oxygenation correlates with mean arterial pressure in critically ill premature infants. Pediatrics 2000;106:625-32.

21) Gilmore MM, Stone BS, Shepard JA, Czosnyka M, Easley RB, Brady KM. Relationship between cerebrovascular dysautoregulation and arterial blood pressure in the premature infant. J Perinatol 2011;31:722-9.

22) Tyszczuk L, Meek J, Elwell C, Wyatt JS. Cerebral blood flow is independent of mean arterial blood pressure in preterm infants undergoing intensive care. Pediatrics 1998;102:337-41.

23) Soul JS, Hammer PE, Tsuji M, Saul JP, Bassan H, Limperopoulos $\mathrm{C}$, et al. Fluctuating pressure-passivity is common in the cerebral circulation of sick premature infants. Pediatr Res 2007;61: 467-73.

24) O'Leary H, Gregas MC, Limperopoulos C, Zaretskaya I, Bassan $\mathrm{H}$, Soul JS, et al. Elevated cerebral pressure passivity is associated with prematurity-related intracranial hemorrhage. Pediatrics 2009;124:302-9.

25) Kaiser JR, Gauss CH, Williams DK. The effects of hypercapnia on cerebral autoregulation in ventilated very low birth weight infants. Pediatr Res 2005;58:931-5.

26) Kaiser J, Gauss C, Williams D. Tracheal suctioning is associated with prolonged disturbances of cerebral hemodynamics in very low birth weight infants. J Perinatol 2007;28:34-41.

27) Kaiser J, Gauss C, Williams D. The effects of closed tracheal suctioning plus volume guarantee on cerebral hemodynamics. J Perinatol 2011;31:671-6.

28) Wong F, Leung T, Austin T, Wilkinson M, Meek J, Wyatt J, et al. Impaired autoregulation in preterm infants identified by using spatially resolved spectroscopy. Pediatrics 2008;121:e604-11.

29) Riera J, Cabanas F, Serrano JJ, Madero R, Pellicer A. New developments in cerebral blood flow autoregulation analysis in preterm infants: a mechanistic approach. Pediatr Res 2016;79: 460-5.

30) Rhee CJ, Fraser III CD, Kibler KK, Easley RB, Andropoulos DB, Czosnyka $\mathrm{M}$, et al. The ontogeny of cerebrovascular pressure autoregulation in human premature infants. J Perinatol 2014;34: 926-31.

31) Nichol J, Girling F, Jerrard W, Claxton E, Burton A. Fundamental instability of the small blood vessels and critical closing pressures in vascular beds. Am J Physiol 1951;164:330-44.

32) Jagersberg M, Schaller C, Bostrom J, Schatlo B, Kotowski M, Thees C. Simultaneous bedside assessment of global cerebral blood flow and effective cerebral perfusion pressure in patients with intracranial hypertension. Neurocrit Care 2010;12:225-33.

33) Varsos GV, Richards H, Kasprowicz M, Budohoski KP, Brady KM, Reinhard M, et al. Critical closing pressure determined 
with a model of cerebrovascular impedance. J Cereb Blood Flow Metab 2013;33:235-43.

34) Panerai R, Coughtrey H, Rennie J, Evans D. A model of the instantaneous pressure-velocity relationships of the neonatal cerebral circulation. Physiol Meas 1993;14:411-8.

35) Panerai R, Kelsall A, Rennie J, Evans D. Estimation of critical closing pressure in the cerebral circulation of newborns. Neuropediatrics 1995;26:168-73.
36) Rhee CJ, Fraser III CD, Kibler KK, Easley RB, Andropoulos DB, Czosnyka M, et al. Ontogeny of critical closing pressure. Pediatr Res 2015;78:71-5.

37) Nelson RJ, Czosnyka M, Pickard JD, Maksymowicz W, Perry S, Lovick AH. Experimental aspects of cerebrospinal hemodynamics: the relationship between blood flow velocity waveform and cerebral autoregulation. Neurosurgery 1992;31:705-10. 